\title{
Maximizing the Smile Symmetry in Facial Paralysis Reconstruction: An Algorithm Based on Twenty Years' Experience
}

\author{
Bernardo Hontanilla, MD, $\mathrm{PhD}^{1}$ Jesus Olivas-Menayo, $\mathrm{MD}, \mathrm{PhD}^{1}$ Diego Marré, $\mathrm{MD}^{1}$ \\ Álvaro Cabello, MD, $\mathrm{PhD}^{1}$ Cristina Aubá, $\mathrm{MD}, \mathrm{PhD}^{1}$
}

${ }^{1}$ Department of Plastic and Reconstructive Surgery, Clínica Universidad de Navarra, Pamplona, Spain

Facial Plast Surg 2021;37:360-369.
Address for correspondence Bernardo Hontanilla, MD, PhD, Department of Plastic and Reconstructive Surgery, Clínica Universidad de Navarra, Av. Pio XII 36, 31008 Pamplona, Spain (e-mail: bhontanill@unav.es).

\begin{abstract}
Over the last two decades, the senior author (B.H.) has had an extensive experience with facial paralysis reconstruction. During this period, the techniques have evolved substantially based on the experience and after observing and analyzing the surgical outcomes. The purpose of this article is to relay the lessons learned from the 20 years' experience and suggest an algorithm. In this retrospective study, we have included 343 cases of facial paralysis cases. Complete facial paralysis cases were 285 and 58 were incomplete facial paralyses, both requiring surgical procedures. Complete facial paralyses were divided in to short term $(n=83)$ and long term $(n=202)$. In total, $58 \%$ of the patients were women and $42 \%$ were men. The age range was 6 to 82 years. The techniques employed were direct suture, nerve grafts, cross-facial nerve grafts (CFNGs), masseteric-to-facial nerve transference, hypoglossal-to-facial nerve transference, free muscle transplants, and lengthening temporal myoplasty to achieve the best symmetry after reanimation of unilateral, bilateral, complete, and incomplete facial paralysis. The type of paralysis, objective measurements, the personal patient's smile, and the gender are key concepts to be considered before scheduling a dynamic facial paralysis reconstruction. For unilateral facial paralysis, the time of onset, the type of paralysis, the patient's comorbidities, and the healthy side status are some of the determining factors when selecting the correct technique. The preferred techniques for unilateral facial paralysis are direct repair, CFNG, masseteric-to-facial transposition, and free gracilis transfer. For incomplete facial paralysis, the masseteric-to-facial nerve transference is preferred. In bilateral facial paralysis, bilateral free gracilis transfer is performed in two stages using the nerve of the masseter muscle as the source of

Keywords

- facial paralysis

- algorithm

- reconstruction innervation. The authors provide an algorithm which simplifies facial paralysis reconstruction to achieve the greatest facial symmetry while thinking about the potential comorbidities and developing spontaneity smile according to the gender of the patient.
\end{abstract}

Issue Theme Facial Plastic Surgery Original Research; Guest Editors: Anthony P. Sclafani, MD, MBA, FACS, and Alwyn D'Souza, MBBS, FRCS Eng, FRCS (ORL-HNS) (c) 2021. Thieme. All rights reserved. Thieme Medical Publishers, Inc., 333 Seventh Avenue, 18th Floor, New York, NY 10001, USA
DOI https://doi.org/ 10.1055/s-0041-1722905. ISSN 0736-6825. 
Facial paralysis reconstruction is one of the most challenging procedures in plastic surgery because it requires the restoration of not only the facial movement, but also the facial expression and spontaneity, which are very important in psychosocial interactions and nonverbal language. In addition, facial paralysis generates a lack of facial tone and negative consequences on essential facial functions such as eyelid closure, oral competence, and phonation, which diminish the quality of life of facial paralysis patients.

The smile is considered a fundamental form of emotional expressions and influences interpersonal judgments and life outcomes. According to our experience and the literature, asymmetry of the smile is usually the main concern of facial paralysis patients. The symmetry has been considered the most important aspect to determine the attractiveness of a face. ${ }^{1}$ Moreover, the smile has been rated as the facial expression with the highest positive emotional response and has been shown to reduce stress. ${ }^{2}$ Hence, the surgical rehabilitation of the oral commissure displacement should restore facial symmetry, both at rest and in active expression, with the normal side in unilateral reconstructions and between both sides in bilateral reconstructions.

Over the past decades, the senior author (B.H.) has performed many facial palsy reconstructions. During this extensive period, the indications of each technique have evolved based on the available technology and, more importantly, on the evaluation of the aesthetic results, complications, and patient satisfaction. The purpose of the present article is to detail different concepts and surgical techniques for facial palsy reconstructions that have shown excellent long-term results and a high patient satisfaction. Furthermore, we want to introduce an algorithm which indicates the best techniques to achieve a balance between symmetry and spontaneity after reconstructing both unilateral and bilateral facial paralyses.

\section{Materials and Methods}

We have seen 652 facial paralysis cases in the last 20-year period. Of these, 263 cases were not included in this study as little deficiencies were presented; for these cases only ocular procedures were performed, such as gold weight implants or botulin toxin infiltration, or the patient decided not to perform any surgical procedure. We have included 389 cases of facial paralysis cases in this study. Complete facial paralysis cases were 285 and 58 were incomplete facial paralysis cases, both requiring surgical procedures. Complete facial paralyses were divided in to short-term $(n=83)$ and longterm $(n=202)$ facial paralyses. When short-term facial paralyses were present, cross-facial nerve grafts (CFNGs; $n=30)$, masseteric nerve transference $(n=32)$, and hypoglossal nerve transfer $(n=21)$ were performed. In long-term facial paralysis, the gracilis muscle is used to connect to a CFNG ( $n=72$ ), or to the masseteric nerve $(n=44)$, or to the hypoglossal nerve $(n=3)$. When microsurgeries were not indicated, a lengthening temporal myoplasty was performed $(n=6)$. Static suspension with the plantaris tendon was indicated in people more than 70 years old $(n=46)$. In total,
$58 \%$ of the patients were women and $42 \%$ were men. The age range was 6 to 82 years.

\section{Results and Discussion}

\section{Unilateral Facial Paralysis}

\section{Dynamic Reconstruction}

The type of paralysis, objective measurements, the personal patient's smile, and the gender are key concepts to be considered before scheduling a dynamic facial paralysis reconstruction.

Objective measurements: The quantification of the facial paralysis is one of the most important aspects when examining patients with facial palsy. Assessing the severity of the paralysis is useful not only for doing a precise diagnosis, but also when deciding a surgical procedure. Subjective methods of evaluation have been described for assessing various facial nerve disorders. ${ }^{3-6}$ These methods have historically been based on scale grades to rank the severity of the damage. In 2015, a systematic review identified 19 facial nerve grading scales. After comparison, only the Sunnybrook Facial Grading Scale satisfied all criteria for an ideal facial nerve grading instrument. ${ }^{7}$ However, these subjective instruments poorly characterize dynamic facial reanimation techniques since the surgeon needs to accurately quantify the damage to know how much should be restored.

In 2008, we introduced the FACIAL CLIMA, an automatic, quantitative, operator-independent, objective method that allows dynamic quantification of facial movements. ${ }^{8}$ The FACIAL CLIMA is used both for preoperative planning and for assessing postoperative outcomes. Using an objective analysis, it is possible to evaluate the degree of symmetry obtained by comparing the reanimated and the normal sides. This is an important aspect to consider when comparing different techniques of facial reanimation between different individuals' smiles. Although the FACIAL CLIMA was described 13 years ago, it is still one of the most precise systems to quantify the facial movements when compared with others, as described by Gerós et al in $2016 .^{9}$

Type of paralysis: Determining the type of paralysis is imperative before deciding a treatment. In this sense, we divide facial paralysis in to complete or incomplete, also known as flaccid and nonflaccid facial paralyses. This distinction is important due to the timing, because in complete facial palsies the facial musculature does not receive neuronal input, the mimic muscles will be irreversibly atrophied if this time exceed 2 years, ${ }^{10}$ and a new muscle unit must be incorporated to restore motion.

Conversely, in an incomplete facial paralysis, the time of onset does not influence because the mimic muscles are receiving axonal input which avoids atrophy. The same techniques could be proposed for incomplete and subacute complete ( 3 months to 2 years) facial paralyses, since the mimic muscles are still viable. Moreover, our experience is that female patients with facial paralysis of up to 4 years can benefit from these techniques, avoiding a muscle transfer. On the other hand, the acute complete (less than 3 months) 
Table 1 Intragroup comparison of commissure displacement and commissure contraction velocity comparing the CFNG and the masseteric transference

\begin{tabular}{|l|l|l|l|l|l|l|}
\hline & \multicolumn{4}{|l|}{ Mean \pm SD CD $(\mathrm{mm})$} & \multicolumn{2}{l|}{ Mean \pm SD CCV $(\mathrm{mm} / \mathrm{s})$} \\
\hline Group & Healthy & Reanimated & $p$-Value & Healthy & Reanimated & $p$-Value \\
\hline I (CFNG) & $8.6 \pm 2.8$ & $6.2 \pm 3.1$ & 0.001 & $33.5 \pm 13.2$ & $23.1 \pm 12.4$ & 0.019 \\
\hline II (masseteric) & $9.1 \pm 3.1$ & $7.9 \pm 2.9$ & 0.52 & $35.6 \pm 12.9$ & $32.0 \pm 14.3$ & 0.35 \\
\hline
\end{tabular}

Abbreviations: CCV, commissure contraction velocity; CD, commissural displacement; CFNG, cross-facial nerve graft; SD, standard deviation.

Table 2 Intergroup comparison of commissure displacement, commissure contraction velocity, and percentage of recovery comparing the CFNG and the masseteric transference

\begin{tabular}{|l|l|l|l|l|l|l|}
\hline & \multicolumn{2}{|l|}{ Healthy side $^{\mathrm{a}}$} & \multicolumn{2}{l|}{ Reanimated side $^{\mathrm{a}}$} & \multicolumn{2}{l|}{${\text { Recovery }(\%)^{\mathrm{a}}}$} \\
\hline Group & CD (mm) & CCV (mm/s) & CD (mm) & CCV (mm/s) & CD & CCV \\
\hline I (CFNG) & $8.6 \pm 2.8$ & $33.5 \pm 13.2$ & $6.2 \pm 3.1$ & $23.1 \pm 12.4$ & $64.2 \pm 26.3$ & $76.8 \pm 29.2$ \\
\hline II (masseteric) & $9.1 \pm 3.1$ & $35.6 \pm 12.9$ & $7.9 \pm 2.9$ & $32.0 \pm 14.3$ & $91.9 \pm 22.2$ & $95.1 \pm 35.6$ \\
\hline$p$ & 0.61 & 0.46 & 0.046 & 0.22 & 0.039 & 0.43 \\
\hline
\end{tabular}

Abbreviations: CCV, commissure contraction velocity; CD, commissural displacement; CFNG, cross-facial nerve graft.

${ }^{\mathrm{a}}$ Mean \pm standard deviation.

Table 3 Intergroup comparison of satisfaction and spontaneity ${ }^{a}$ comparing the CFNG and the masseteric transference

\begin{tabular}{|l|l|l|}
\hline Group & SP:NSP ratio (SP\%) & SS:NSS ratio (\% SS) \\
\hline I (CFNG) & $8: 2(80.0 \%)$ & $8: 2(80.0 \%)$ \\
\hline II (masseteric) & $16: 2(88.8 \%)$ & $10: 8(55.5 \%)$ \\
\hline$p$ & 0.60 & 0.25 \\
\hline
\end{tabular}

Abbreviations: CFNG, cross-facial nerve graft; NSP, nonsatisfied patients; NSS, nonspontaneous smile; SP, satisfied patients; SS, spontaneous smile. aFisher's exact test shows no significant differences in satisfaction and spontaneity between the groups.

facial paralysis could be restored by direct nerve repair or providing a new nerve source as the CNFG or the masseteric nerve. ${ }^{11}$ In our series, when comparing the use of both nerves ( $n=17$ and 26, respectively), we observed that the masseteric nerve achieves more symmetry and commissural displacement and satisfaction of spontaneity (especially in women) than the CFNG (-Tables 1-3).

Patient's smile: Before indicating a surgical facial reanimation, the normal side smile should be thoroughly analyzed. The two most important factors that characterize the smile are the vector and the strength of pull. Both factors show a great interpersonal difference as established by Rubin, who classified the smile in three anatomical types. ${ }^{12}$ However, he concluded that all types of smile overlap in a greater or a lesser degree, and consequently, infinite types of smile can be found.

Vector of the smile: Although we identify it by the FACIAL CLIMA system, the vector of the smile can easily be identified on photographs of the healthy side at rest and at maximal commissure displacement. By superimposing both images, the resultant vector of oral commissural movement above the horizontal can be used to reconstruct the paralyzed side (-Fig. $\mathbf{1}$ ).
This vector is very important for the muscle orientation during flap inset when reanimating long-term complete facial paralysis. The flap should be transferred to the face and fixed to the modiolus and zygomatic arch using the same vector that is in the healthy side. However, the vector is not relevant in complete short-term or incomplete facial paralysis because the facial musculature is not atrophied yet, and consequently the patient's vector smile is preserved.

Strength of the smile: Smiles are different between individuals regarding the commissural displacement. For example, a patient with a strong smile can have a higher value of commissural displacement than someone with a "weak" smile, without meaning that the latter has some form of paralysis. After retrospectively analyzing our sample and our results, the cut-off point to determine if a smile is strong or weak has been established at $8 \mathrm{~mm}$ of commissural displacement. Thus, a patient with a healthy side commissural displacement of less than $8 \mathrm{~mm}$ is considered to have a weak smile. Conversely, a patient with a healthy side commissural displacement greater than or equal to $8 \mathrm{~mm}$ is considered to have a strong smile. This simple smile classification has enabled us to indicate the techniques that achieve 


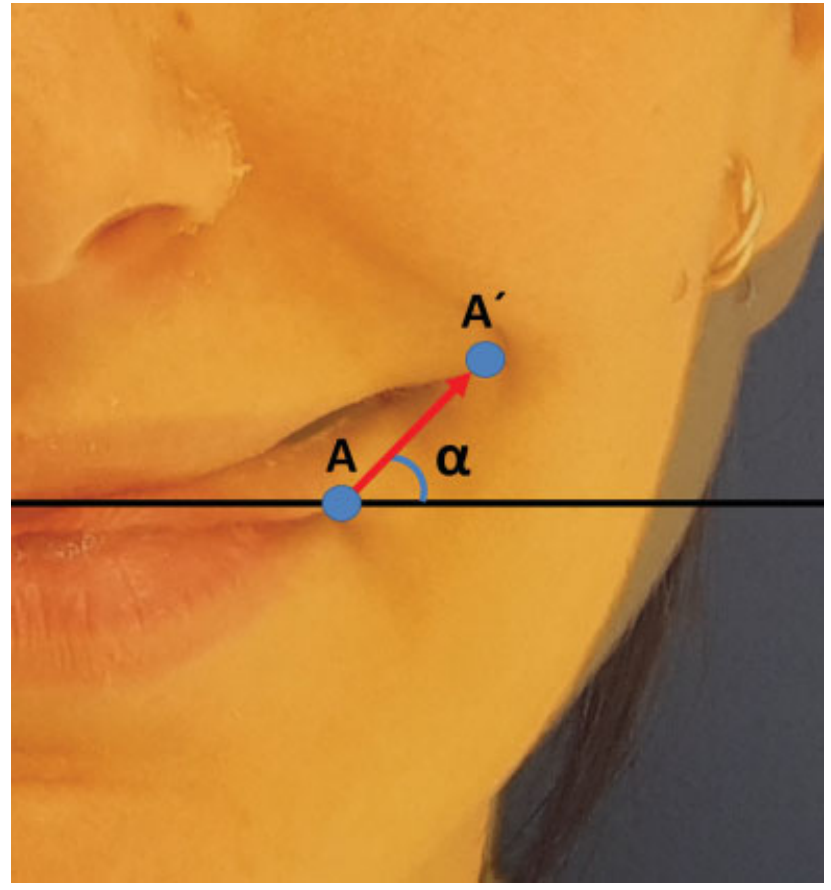

Fig. 1 Vector of the smile obtained after superimposing images of the oral commissure at rest and at maximal displacement. (A) Oral commissure at rest. $\left(\mathrm{A}^{\prime}\right)$ Maximal commissural displacement. $\alpha$ : angle of the vector of the smile.

less commissural displacement for the first group of patients, and the most powerful techniques for the latter. Once we introduced this classification in our practice, we have observed a greater improvement in the symmetry of our patients' face after performing smile reconstruction. For this reason, the accurate quantitative preoperative analysis is very important before deciding a surgical technique for facial paralysis reanimation.

Gender: Numerous publications have shown that in different circumstances, women smile more than men. ${ }^{13,14}$ Thus, it is reasonable to think that the motivational drive toward smiling is greater in women and therefore it is very likely that after smile reanimation, female population develops brain plasticity earlier than men on the basis that smiling is more important for them.

Several studies have shown a dichotomy between the sexes in nerve regeneration and brain plasticity. Regarding the former, evidence that supports the fact that women recover from neural injury faster than men is abundant. ${ }^{15-18}$ Over the years, we have seen that women defend better from nerve injury and thus are more resistant than men to denervation and muscle atrophy, maybe influenced by sex hormones. These observations have led us to perform techniques indicated for palsy of short duration in women with longstanding disease achieving good functional and aesthetic results. ${ }^{19,20}$ This factor is especially important in those cases which are between short and longstanding facial paralyses. In our series, comparison between genders of movement recovery in patients with CFNG performed with more than 2 years of evolution and of movement dissociation in patients reanimated using the masseteric nerve shows that women's recovery and the possibility of dissociation of smile are better than in men ( - Table 4 ).

Regarding brain plasticity, our studies have shown that female patients could develop an earlier cortical adaptation than male patients after smile reconstruction with nerves other than the facial, developing spontaneity and dissociation at a higher rate and earlier than male patients. ${ }^{20,21}$ Although we are unable to predict which patients will achieve dissociation and spontaneity after facial reanimation using nonfacial donor nerves, this must be taken into account when deciding a technique to get both symmetry and potential development of spontaneity.

\section{Surgical Techniques for Unilateral Facial Paralysis}

Direct nerve repair: The most desirable scenario when reconstructing the facial nerve is a direct nerve repair. This will only be possible if the time of onset is short (less than 3 months) and the proximal facial nerve stump and the different distal branches are identifiable. When planning a direct nerve repair, the length of the nerve gap and the vascularity of the surrounding recipient bed should be taken into consideration. If the length of the gap is less than $1 \mathrm{~cm}$, the direct nerve repair between both ends could be an option as long as there is no tension. If the gap is greater or the nerve coaptation is under tension, nerve graft is a preferable option.

Our group most frequently employs the sural nerve as a donor autograft due to its well-known advantages. Although the morbidity of the sural nerve is considered minimal, it should be informed to the patients, an area of sensory loss of approximately the size of 5 to $6 \mathrm{~cm}$ is to be expected, and 20 to $30 \%$ of the patients experienced minimal levels of pain, cold sensitivity, functional impairment, and scar discomfort. ${ }^{22}$

Table 4 Comparison between genders of movement recovery in patients with CFNG performed with more than 2 years of evolution and of movement dissociation in patients reanimated using the masseteric nerve

\begin{tabular}{|c|c|c|c|}
\hline Outcome & Female, $\boldsymbol{n}(\%)$ & Male, $n(\%)$ & $p$-Value \\
\hline \multicolumn{4}{|l|}{ Movement restoration } \\
\hline - CFNG $>2$ y & $28(80)$ & $0(0)$ & 0.02 \\
\hline - HNT > 2 y & $19(100)$ & $2(33.3)$ & 0.04 \\
\hline \multicolumn{4}{|l|}{ Movement dissociation } \\
\hline - Gracilis to masseteric & $31(73.3)$ & $13(25)$ & 0.02 \\
\hline
\end{tabular}

Abbreviations: CFNG, cross-face nerve graft; HNT, hypoglossal nerve transposition.

Note: Fisher's exact test shows significantly higher recovery and dissociation in females. 
After harvesting the nerve graft, it should be split in as many fascicules as the number of sectioned branches that need reconstruction, each of which will be connected to the transected facial nerve branches. On the other hand, the vascularization of the surrounded tissue must be confirmed with the aim to safeguard the viability of the nerve graft. In those cases where the sural nerve graft lays directly over a completely avascular bed, for example, after a radiation therapy or aggressive surgical resections, a superficial temporofascial flap should be harvested to wrap around the nerve circumferentially without tension or compression and sutured to the surrounding tissues to avoid damage from pulling, tearing, or retraction. ${ }^{23}$ Regarding oncologic adjuvant therapies, our group has demonstrated that the administration of brachytherapy during the immediate postoperative period followed by external beam radiotherapy does not affect the functional outcomes of facial nerve repair with interpositional grafts. ${ }^{24}$ When the proximal stump is not available, a CFNG or a masseteric transposition can be done.

Cross-face nerve grafting: The CFNG has been devised to help restore a smile that is apparently spontaneous and coordinated with the contralateral side. In these techniques, motor axons from the normal facial nerve are delivered to the contralateral paralyzed side. Despite the main advantages of this technique, it also has some disadvantages. First, two stages are required, although some authors have advocated a one-stage procedure. In this sense, Frey et al recommend one-stage CFNG with end-to-side coaptation distally on the recipient nerve of the paralyzed side, although the real advantages over traditional techniques remain to be investigated. ${ }^{25}$ Despite the aforementioned variation, we still prefer a two-stage approach to ensure that the axonal load grows exclusively from the healthy side to the affected side, especially important when reconstructing incomplete facial paralysis. ${ }^{26}$ Once Tinel's sign is noted when tapping the paretic side, the second stage can be performed.

Another disadvantage of CFNG is that it needs a donor nerve, which, as we have explained, carries some morbidity. Furthermore, when a nerve graft is used, the axons must cross two sites of coaptation, which may result in suboptimal reinnervation of the target muscle. ${ }^{27}$ However, this loss of axons could be beneficial when reconstructing weak smiles, especially in the male population who develop spontaneity and dissociation at a lower rate when using nonfacial donor nerves. For this reason, CFNG is our technique of choice in these cases.

Masseteric-to-facial transposition: Masseteric-to-facial nerve transposition has gained increasing popularity in the reanimation of both complete and incomplete facial paraly$\operatorname{ses}^{28-32}$ (- Fig. 2; - Videos 1 and 2).

\section{Video 1}

Preoperative appearance of a 34-year-old man with incomplete right facial paralysis after a partially recovered Bell's palsy. Online content including video sequences viewable at: https://www.thieme-connect. com/products/ejournals/html/10-1055-s-00411722905 .

\section{Video 2}

The same patient from video 1 after facial reanimation by masseteric nerve transfer at 12 months after surgery. Online content including video sequences viewable at: https://www.thieme-connect.com/products/ejournals/ html/10-1055-s-0041-1722905.

The nerve of the masseter offers several advantages for facial reanimation. First, it is a one-stage procedure, in contrast with CFNG. Second, its strength of pull allows, on the one hand, reanimation of strong smiles and, on the other hand, acquisition of very good symmetry at rest and when smiling. Third, the proximity between the masseteric nerve and branches of the facial nerve eliminates the need for use a nerve graft, and thus reduces the morbidity of the donor site and avoids the loss of power that is attributed to the use of grafts when there are two coaptation sites. Lastly, the possibility of developing spontaneity, as noted above, with higher rates and earlier in women than in men. ${ }^{19,20}$ Thus,
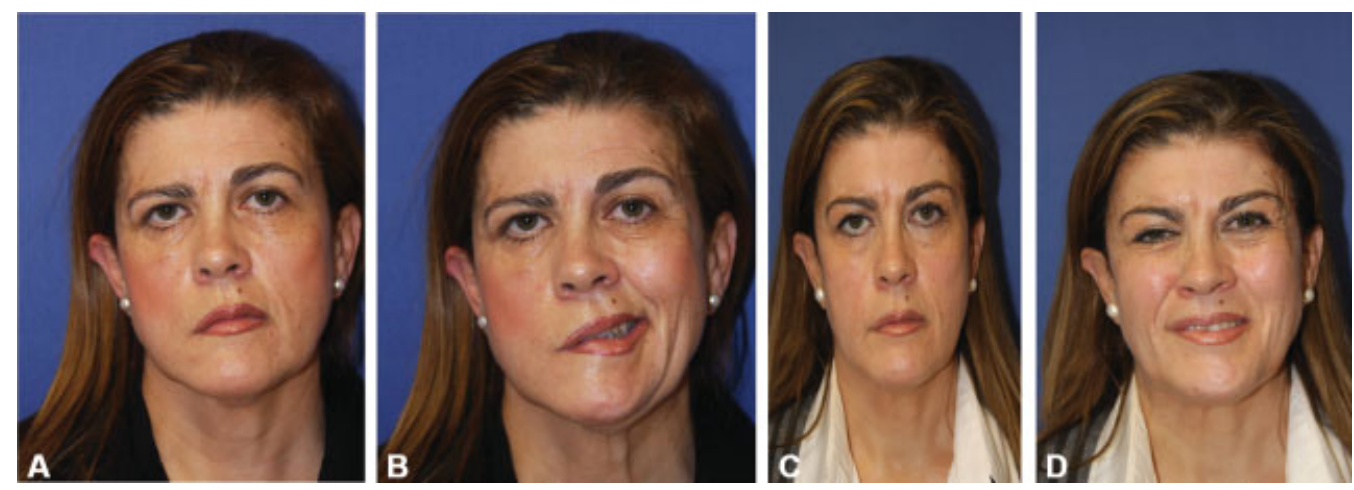

Fig. 2 A 51-year-old woman with right facial paralysis secondary to varicella zoster infection. Masseteric nerve transfer was performed for smile reanimation. Preoperative appearance at rest (A) and while smiling (B). Postoperative situation after 2 years, at rest (C) and while smiling (D). 
Table 5 Intergroup comparisons of age and time of evolution of paralysis comparing the masseteric (group I) and the hypoglossal transference (group II)

\begin{tabular}{|c|c|c|c|c|c|c|c|c|c|}
\hline & \multirow[t]{2}{*}{ Age (y) } & \multirow[t]{2}{*}{ Time (mo) } & \multicolumn{2}{|l|}{$\begin{array}{l}\mathrm{CD}(\mathrm{mm}) \\
(\mathrm{mean} \pm \mathrm{SD})\end{array}$} & \multicolumn{2}{|l|}{$\begin{array}{l}\mathrm{CCV}(\mathrm{mm} / \mathrm{s}) \\
(\text { mean } \pm \mathrm{SD})\end{array}$} & \multicolumn{2}{|c|}{$\begin{array}{l}\text { Recovery (\%) } \\
(\text { mean } \pm S D)\end{array}$} & \multirow[b]{2}{*}{ Recovery (d) } \\
\hline & & & Reanimated & Normal & Reanimated & Normal & $C D$ & $\mathrm{CCV}$ & \\
\hline Group I & $49.5 \pm 8.3$ & $16.4 \pm 5.3$ & $7.7 \pm 3.9$ & $9.3 \pm 3.9$ & $35.3 \pm 16.7$ & $48.7 \pm 19$ & $83.2 \pm 4.5$ & $72.5 \pm 17$ & $136 \pm 7.4$ \\
\hline Group II & $44.1 \pm 7.6$ & $17.1 \pm 4.8$ & $7.8 \pm 3.1$ & $8.5 \pm 2.7$ & $36.2 \pm 10.6$ & $45.4 \pm 12.6$ & $91.8 \pm 5.1$ & $79.7 \pm 15.5$ & $62 \pm 4.6$ \\
\hline$p$ & 0.52 & 0.61 & 0.54 & 0.41 & 0.5 & 0.39 & 0.11 & 0.19 & 0.013 \\
\hline
\end{tabular}

Abbreviations: CCV, commissural contraction velocity; $C D$, commissure displacement; SD, standard deviation. Note: Evaluated parameters (i.e., CD and CCV), percentage of recovery, and time of recovery are shown.

Table 6 Intragroup comparisons of CD and CCV comparing the masseteric and the hypoglossal transference

\begin{tabular}{|c|c|c|c|c|c|c|}
\hline & \multicolumn{3}{|c|}{$\begin{array}{l}C D(\mathrm{~mm}) \\
\text { mean } \pm S D\end{array}$} & \multicolumn{3}{|l|}{$\begin{array}{l}\mathrm{CCV}(\mathrm{mm} / \mathrm{s}) \\
\text { mean } \pm \mathrm{SD}\end{array}$} \\
\hline & Healthy & Reconstructed & $p$-Value & Healthy & Reconstructed & $p$-Value \\
\hline Group I & $9.3 \pm 3.9$ & $7.7 \pm 3.9$ & 0.017 & $48.7 \pm 19$ & $35.3 \pm 16.7$ & 0.036 \\
\hline Group II & $8.5 \pm 2.7$ & $7.8 \pm 3.1$ & 0.2 & $45.4 \pm 12.6$ & $36.2 \pm 10.6$ & 0.17 \\
\hline
\end{tabular}

Abbreviations: CCV, commissural contraction velocity; CD, commissure displacement; SD, standard deviation.

Note: Significant differences are observed in group I (masseteric) for both parameters.

when comparing the masseteric nerve versus hypoglossal nerve, we observed better results in the masseteric group than in the hypoglossal group (-Tables $\mathbf{5}$ and $\mathbf{6}$ ).

Furthermore, our working group has demonstrated the existence of cortical overlapping between smile and jawclenching cerebral areas in normal healthy volunteers. ${ }^{33}$ On the other hand, a study published in 2017 demonstrated a strong coactivation between the masseter muscle and the zygomaticus major, suggesting that the masseter nerve may be preferred in smile reanimation over other nonfacial nerves such as hypoglossal or spinal nerves. ${ }^{34}$ For this reason, masseteric-to-facial transposition has become our first-choice surgical technique in both incomplete and short-term complete facial paralyses for the female population, ${ }^{11,35}$ even in patients with weak smiles due to their brain plasticity and the capacity to modulate the strength of the pull to achieve symmetry.

Gracilis transfer:Longstanding unilateral facial paralysis is best addressed with free muscle transplantation to restore the face motion, because there is no viable facial musculature. Like other authors, the gracilis muscle is our preferred option. ${ }^{36-38}$ After harvesting the flap, the most powerful branch of the obturator nerve should be used for the nerve coaptation. If two or more branches have the same strength, we should include all of them in our nerve coaptation to ensure the correct reinnervation of the flap.

The position of the muscular flap should imitate the contralateral zygomaticus major muscle to obtain the same vector of the smile, thus the preoperative healthy side analysis is imperative. Although some variations and refinements have been described to improve the symmetry when using gracilis free flap, ${ }^{39,40}$ from our experience, recreating the same zygomaticus-modiolus vector as in the healthy side has optimal outcomes. Once the muscle is fixed in its position, the correct movement and position of both oral commissure and nasolabial fold should be checked by using a nerve stimulator. Neurotization can be obtained from the cross-facial or the masseter nerve ${ }^{41}$; however, the same distinction regarding the smile (weak or strong) and gender should be done to obtain excellent results ( - Fig. 3; - Videos $\mathbf{3}$ and $\mathbf{4}$ ).

\section{Video 3}

Preoperative appearance of a 67-year-old woman with complete left facial paralysis. Online content including video sequences viewable at: https://www. thieme-connect.com/products/ejournals/html/101055-s-0041-1722905.

\section{Video 4}

The same patient from video 3 after facial reanimation by gracilis transfer at 12 months after surgery. Online content including video sequences viewable at: https:// www.thieme-connect.com/products/ejournals/html/ 10-1055-s-0041-1722905.

When performing a free flap is not possible or the patient rejects it, a lengthening temporalis myoplasty is a good alternative. ${ }^{42,43}$ The temporalis muscle has the same nerve source as the masseteric nerve, that is to say the 

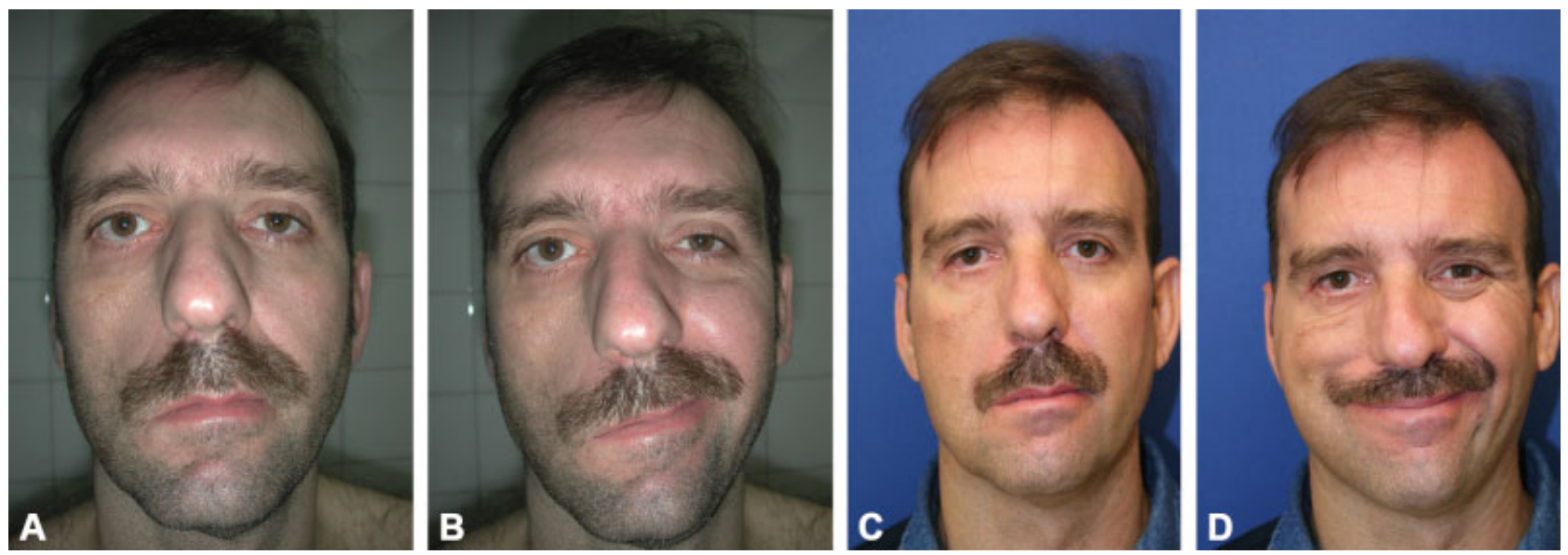

Fig. 3 A 40-year-old man with right facial paralysis secondary to acoustic neurinoma resection 8 years previously. Preoperative appearance at rest $(A)$ and when smiling (B). A gracilis muscle transplant connected to a cross-facial nerve graft was performed. The patient 2 years postoperatively at rest (C) and when smiling (D).

trigeminal nerve, therefore the indication for this technique would be especially useful in women because of their higher rate of spontaneity when using a nonfacial nerve (-Videos 5 and $\mathbf{6})$.

\section{Video 5}

Preoperative appearance of a 69-year-old man with complete left facial paralysis. Online content including video sequences viewable at: https://www. thieme-connect.com/products/ejournals/html/101055-s-0041-1722905.

\section{Video 6}

The same patient from video 5 after facial reanimation by lengthening temporalis myoplasty at 12 months after surgery. Online content including video sequences viewable at: https://www.thieme-connect. com/products/ejournals/html/10-1055-s-0041-

1722905.

\section{Bilateral Facial Paralysis}

Bilateral facial paralysis is a rare clinical condition with an incidence of one per 5 million and an occurrence of 0.3 to $2 \%$ in facial paralysis cases, ${ }^{44,45}$ sometimes in the context of Möbius syndrome. Our preferred technique in bilateral cases is a bilateral-staged free gracilis transfer with a period of 6 months between the surgeries as reported by several authors. ${ }^{46-48}$ The flap is transferred to the face and fixed to the modiolus and zygomatic arch recreating the zygomaticus major muscle. In bilateral cases, there is no healthy side from which to reference the vector; therefore, a study in normal subjects has proposed a vector of $40^{\circ}$ to $48^{\circ}$ above the horizontal ${ }^{49}$ to be used in these patients.
Regarding the nerve source, since both facial nerves are damaged in bilateral cases, it is necessary to use other nerves such as the hypoglossal, the accessory nerve, or the masseter branch of the trigeminal nerve. Our preferred option is the masseteric nerve because it achieves a strong symmetrical smile, which is properly controlled by the patient, recreating a smile similar to a normal one..$^{50}$ In addition, with practice it is possible to develop a spontaneous smile. Although the use of hypoglossal nerve has been relegated because of the morbidity caused by its loss, and is only used when the nerve to the masseter is not available, it should be considered as the first option as a donor motor nerve by performing an end-to-side coaptation with minimum repercussion in speech or swallowing. ${ }^{51}$

Admittedly, the same technique should be done on both sides to achieve the maximum level of symmetry (-Videos 7 and 8).

\section{Video 7}

Preoperative appearance of a 4-year-old girl with bilateral facial paralysis secondary to Möbius Syndrome. The patient presented an aberrant movement in the right side which was surgically denervated. Online content including video sequences viewable at: https://www.thieme-connect.com/ products/ejournals/html/10-1055-s-0041-1722905.

\section{Video 8}

The same patient from video 7 after facial reanimation by a bilateral gracilis transfer innervated with masseteric nerve at 12 months after surgery. Online content including video sequences viewable at: https:// www.thieme-connect.com/products/ejournals/html/ 10-1055-s-0041-1722905. 
As we have explained previously, bilateral facial paralysis reconstruction requires two surgeries with a period of 6 months between them. However, our group has reported a Möbius syndrome case in which after unilateral reconstruction, the patient discovered what it was to smile and how it should be done, achieving a bilateral movement. ${ }^{52,53}$

\section{Static Facial Palsy Reconstruction}

When the patient is more than 70 years old and/or has several comorbidities, a static technique is indicated. Our preferred technique is to perform a suspension of the nasolabial fold and the oral commissure by a plantaris sling, although fascia lata and palmaris longus can also be used. ${ }^{54}$ This simpler technique achieves good symmetry at rest and it also solves the drooping of the oral commissure and enhances the oral competence (-Fig. 4).

In summary, considering the variety of techniques available, choosing the right technique for facial palsy reanimation in each type of patient is probably one of the most challenging aspects. To aid this decision making, we suggest a
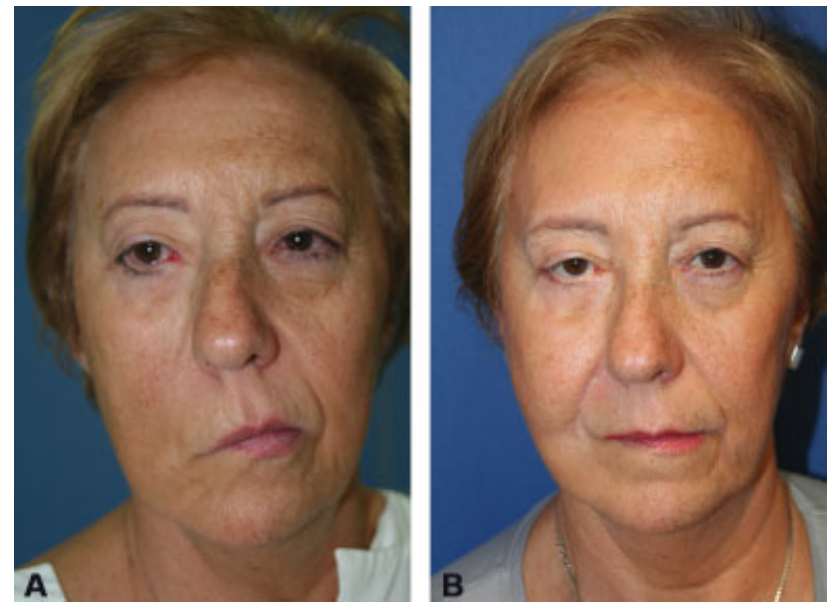

Fig. 4 A 74-year-old woman with right complete facial. Preoperatively (A) and postoperatively (B) after performing a static facial paralysis reconstruction.

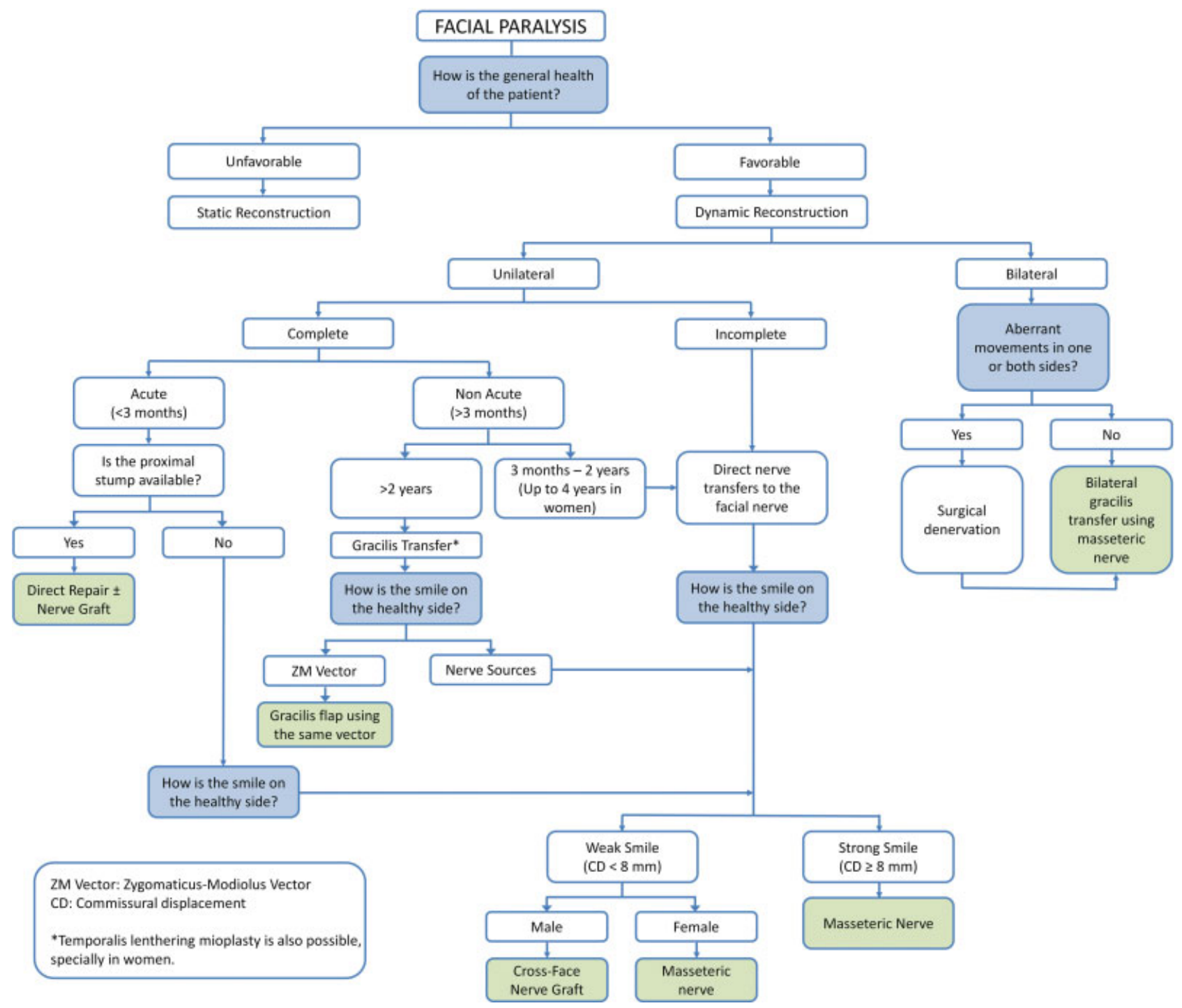

Fig. 5 Algorithm for treating facial paralysis depending on the comorbidities, timing, patient's gender, kind of smile, and paralysis type. 
treatment algorithm given our experience and current concepts on the topic, in an attempt to bring us closer to the goal for reanimating unilateral, bilateral, or complete and incomplete facial palsies with the appropriate symmetry, synchrony, and spontaneity (-Fig. 5).

\section{Disclosure}

The authors of this article have not received any financial support.

\section{Conflict of Interest \\ None declared.}

\section{Acknowledgments}

The authors especially thank all members of the Department of Plastic, Aesthetic, and Reconstructive Surgery at the Clinica Universidad de Navarra in the past 20 years for their help in managing the patients at the hospital especially in the operating room.

\section{References}

1 Jones RM, Victor JD, Conte MM. Detecting symmetry and faces: separating the tasks and identifying their interactions. Atten Percept Psychophys 2012;74(05):988-1000

2 Kraft TL, Pressman SD. Grin and bear it: the influence of manipulated facial expression on the stress response. Psychol Sci 2012;23 (11):1372-1378

3 House JWBD, Brackmann DE. Facial nerve grading system. Otolaryngol Head Neck Surg 1985;93(02):146-147

4 Vrabec JT, Backous DDDH, Djalilian HR, et al;Facial Nerve Disorders Committee. Facial nerve grading system 2.0. Otolaryngol Head Neck Surg 2009;140(04):445-450

5 Ross BG, Fradet G, Nedzelski JM. Development of a sensitive clinical facial grading system. Otolaryngol Head Neck Surg 1996;114(03):380-386

6 Coulson SE, Croxson GR, Adams RD, O'Dwyer NJ. Reliability of the "Sydney," "Sunnybrook," and "House Brackmann" facial grading systems to assess voluntary movement and synkinesis after facial nerve paralysis. Otolaryngol Head Neck Surg 2005;132(04):543-549

7 Fattah AY, Gurusinghe ADR, Gavilan J, et al;Sir Charles Bell Society. Facial nerve grading instruments: systematic review of the literature and suggestion for uniformity. Plast Reconstr Surg 2015;135(02):569-579

8 Hontanilla B, Aubá C Automatic three-dimensional quantitative analysis for evaluation of facial movement. J Plast Reconstr Aesthet Surg 2008;61(01):18-30

9 Gerós A, Horta R, Aguiar P. Facegram - objective quantitative analysis in facial reconstructive surgery. J Biomed Inform 2016; 61:1-9

10 Terzis JK, Olivares FS. Long-term outcomes of free-muscle transfer for smile restoration in adults. Plast Reconstr Surg 2009;123(03): 877-888

11 Hontanilla B, Olivas J, Cabello Á, Marré D Cross-face nerve grafting versus masseteric-to-facial nerve transposition for reanimation of incomplete facial paralysis: a comparative study using the FACIAL CLIMA evaluating system. Plast Reconstr Surg 2018;142(02): 179e-191e

12 Rubin LR. The anatomy of a smile: its importance in the treatment of facial paralysis. Plast Reconstr Surg 1974;53(04):384-387

13 Ellis L. Gender differences in smiling: an evolutionary neuroandrogenic theory. Physiol Behav 2006;88(4-5):303-308

14 LaFrance M, Hecht MA, Paluck EL. The contingent smile: a metaanalysis of sex differences in smiling. Psychol Bull 2003;129(02): 305-334
15 Jones KJ. Recovery from facial paralysis following crush injury of the facial nerve in hamsters: differential effects of gender and androgen exposure. Exp Neurol 1993;121(01):133-138

16 Kovacic U, Zele T, Osredkar J, Sketelj J, Bajrović FF. Sex-related differences in the regeneration of sensory axons and recovery of nociception after peripheral nerve crush in the rat. Exp Neurol 2004;189(01):94-104

17 Kume-Kick J, Strand FL. Sex hormones affect muscle contractility and motor functional recovery following peroneal nerve crush. Exp Neurol 1994;128(01):115-123

18 Wagner R, DeLeo JA, Coombs DW, Myers RR. Gender differences in autotomy following sciatic cryoneurolysis in the rat. Physiol Behav 1995;58(01):37-41

19 Marre D, Hontanilla B. Gender differences in facial paralysis reanimation. Plast Reconstr Surg 2012;129(01):190e-192e

20 Hontanilla B, Marre D. Differences between sexes in dissociation and spontaneity of smile in facial paralysis reanimation with the masseteric nerve. Head Neck 2014;36(08):1176-1180

21 Hontanilla B, Cabello A. Spontaneity of smile after facial paralysis rehabilitation when using a non-facial donor nerve. J Craniomaxillofac Surg 2016;44(09):1305-1309[Internet]

22 IJpma FFA, Nicolai JPA, Meek MF. Sural nerve donor-site morbidity: thirty-four years of follow-up. Ann Plast Surg 2006;57(04): 391-395

23 Hontanilla B, Cabello A, Marre D, Manrique M. Wrapping a facial nerve graft in a superficial temporofascial flap to optimise vascularisation: technical note. Br J Oral Maxillofac Surg 2016; 54(04):466-468

24 Hontanilla B, Qiu SS, Marré D Effect of postoperative brachytherapy and external beam radiotherapy on functional outcomes of immediate facial nerve repair after radical parotidectomy. Head Neck 2014;36(01):113-119

25 Frey M, Giovanoli P, Michaelidou M. Functional upgrading of partially recovered facial palsy by cross-face nerve grafting with distal end-to-side neurorrhaphy. Plast Reconstr Surg 2006; 117(02):597-608

26 Hontanilla B, Marre D, Cabello A. Cross-face nerve grafting for reanimation of incomplete facial paralysis: quantitative outcomes using the FACIAL CLIMA system and patient satisfaction. J Reconstr Microsurg 2014;30(01):25-30

27 Frey M, Happak W, Girsch W, Bittner RE, Gruber H. Histomorphometric studies in patients with facial palsy treated by functional muscle transplantation: new aspects for the surgical concept. Ann Plast Surg 1991;26(04):370-379

28 Hontanilla $B$, Marré D Comparison of hemihypoglossal nerve versus masseteric nerve transpositions in the rehabilitation of short-term facial paralysis using the Facial Clima evaluating system. Plast Reconstr Surg 2012;130(05):662e-672e

29 Hontanilla B, Qiu SS. Transposition of the hemimasseteric muscle for dynamic rehabilitation of facial paralysis. J Craniofac Surg 2012;23(01):203-205

30 Yoshioka N. Masseteric nerve as "baby sitter" procedure in incomplete facial paralysis. Plast Reconstr Surg Glob Open 2016;4(04):e669

31 Bianchi B, Ferri A, Ferrari S, Copelli C, Salvagni L, Sesenna E. The masseteric nerve: a versatile power source in facial animation techniques. Br J Oral Maxillofac Surg 2014;52(03):264-269

32 Coombs CJ, Ek EW, Wu T, Cleland H, Leung MK. Masseteric-facial nerve coaptation-an alternative technique for facial nerve reinnervation. J Plast Reconstr Aesthet Surg 2009;62(12): 1580-1588

33 Buendia J, Loayza FR, Luis EO, Celorrio M, Pastor MA, Hontanilla B. Functional and anatomical basis for brain plasticity in facial palsy rehabilitation using the masseteric nerve. J Plast Reconstr Aesthet Surg 2016;69(03):417-426

34 Jensson D, Enghag S, Bylund N, et al. Cranial nerve coactivation and implication for nerve transfers to the facial nerve. Plast Reconstr Surg 2018;141(04):582e-585e 
35 Hontanilla B, Marre D, Cabello A. Masseteric nerve for reanimation of the smile in short-term facial paralysis. $\mathrm{Br} J$ Oral Maxillofac Surg 2014;52(02):118-123

36 Manktelow RT, Tomat LR, Zuker RM, Chang M. Smile reconstruction in adults with free muscle transfer innervated by the masseter motor nerve: effectiveness and cerebral adaptation. Plast Reconstr Surg 2006;118(04):885-899

37 Bae YC, Zuker RM, Manktelow RT, Wade S. A comparison of commissure excursion following gracilis muscle transplantation for facial paralysis using a cross-face nerve graft versus the motor nerve to the masseter nerve. Plast Reconstr Surg 2006;117(07): 2407-2413

38 Hontanilla B, Vila A. Comparison of hemihypoglossal-facial nerve transposition with a cross-facial nerve graft and muscle transplant for the rehabilitation of facial paralysis using the facial clima method. J Plast Surg Hand Surg 2012;46(01):25-31

39 Boahene KO, Owusu J, Ishii L, et al. The multivector gracilis free functional muscle flap for facial reanimation. JAMA Facial Plast Surg 2018;20(04):300-306

40 Greene JJ, Tavares J, Guarin DL, Jowett N, Hadlock T. Surgical refinement following free gracilis transfer for smile reanimation. Ann Plast Surg 2018;81(03):329-334

41 Hontanilla B, Marre D, Cabello A. Facial reanimation with gracilis muscle transfer neurotized to cross-facial nerve graft versus masseteric nerve: a comparative study using the FACIAL CLIMA evaluating system. Plast Reconstr Surg 2013;131(06): 1241-1252

42 Guerreschi P, Labbe D. Lengthening temporalis myoplasty: a surgical tool for dynamic labial commissure reanimation. Facial Plast Surg 2015;31(02):123-127

43 Bos R, Reddy SG, Mommaerts MY. Lengthening temporalis myoplasty versus free muscle transfer with the gracilis flap for long- standing facial paralysis: a systematic review of outcomes. J Craniomaxillofac Surg 2016;44(08):940-951

44 Price T, Fife DG. Bilateral simultaneous facial nerve palsy. J Laryngol Otol 2002;116(01):46-48

45 Gaudin RA, Jowett N, Banks CA, Knox CJ, Hadlock TA. Bilateral facial paralysis: a 13-year experience. Plast Reconstr Surg 2016; 138(04):879-887

46 Zuker RM, Goldberg CSMR, Manktelow RT. Facial animation in children with Möbius syndrome after segmental gracilis muscle transplant. Plast Reconstr Surg 2000;106(01):1-8, discussion 9

47 Terzis JK, Noah EM. Dynamic restoration in Möbius and Möbiuslike patients. Plast Reconstr Surg 2003;111(01):40-55

48 Manktelow RT, Zuker RM. Muscle transplantation by fascicular territory. Plast Reconstr Surg 1984;73(05):751-757

49 Sawyer AR, See M, Nduka C. Quantitative analysis of normal smile with 3D stereophotogrammetry-an aid to facial reanimation. J Plast Reconstr Aesthet Surg 2010;63(01):65-72

50 Hontanilla B, Rodriguez-Losada G. Bilateral reconstruction of smile through muscular transplants neurotized to masseter nerves. J Craniofac Surg 2011;22(03):1099-1100

51 Hontanilla B, Aubá C Smile reconstruction through bilateral muscular transplants neurotized by hypoglossal nerves. J Craniofac Surg 2011;22(03):845-847

52 Marré D, Hontanilla B. Brain plasticity after unilateral reconstruction in Möbius syndrome. Plast Reconstr Surg 2011;128(01):15e-17e

53 Marre D, Hontanilla B. Brain plasticity in Möbius syndrome after unilateral muscle transfer: case report and review of the literature. Ann Plast Surg 2012;68(01):97-100

54 Hontanilla B, Marre D. Eyelid reanimation with gold weight implant and tendon sling suspension: evaluation of excursion and velocity using the FACIAL CLIMA system. J Plast Reconstr Aesthet Surg 2013;66(04):518-524 